\section{ON ALLARTON'S OPERATION FOR STONE IN THE BLADDER.}

\author{
BY BARNARD HOLT, Esq., F.R.C.S., \\ SURGEON TO THE WESTMINSTER HOSPITAL, ETC.
}

Mr. Allakton's operation for stone in the bladder having engaged the attention of operating surgeons, it behoves all those who have had an opportunity of performing it to record their experience of its results.

The main objections which have been hitherto urged against its performance have been in reference to the size of the stone and the enlargement of the prostate gland, the consequent difficulty of extraction, and the effect of forcible dilatation on the neck of the bladder. Having lately performed this operation three times, where these difficulties were prominent features in each case, I desire to record the results.

J. R-, a child aged eight years, was admitted into the Westminster Hospital under my care, April, 1860, suffering from stone in the bladder. The symptoms had existed for eight months prior to his admission, and consisted in difficulty and frequency of micturition, which required considerable straining to effect; occasional passage of bloody urine; and, but rarely, pain at the extremity of the penis. The boy having been placed under the influence of chloroform, a sound was passed to the neck of the bladder, where its further progress was arrested by some foreign body, which a slight amount of pressure sufficed to displace. The sound being thus fairly introduced, a stone was immediately detected, which, from the extent of surface traversed, appeared to be large.

I decided on performing Mr. Ailarton's operation. On May 8th, while under chloroform, a staff as large as the urethra would admit was introduced, and the stone immediately detected. The child was now secured in the ordinary manner, and the forefinger of the left hand being passed into the rectum, the exact situation of the prostate was ascertained. A sharppointed and somewhat triangular knife was now thrust into the mesian line of the perinæum, with the back towards and about three lines in front of the anus, the finger in the rectum guiding the knife, and preventing its being wounded. An incision was now made directly upwards, and the groove of the staff cut into by opening the urethra immediately in front of the prostate; and the knife was now run backwards and forwards to a slight extent so that it might be fairly divided, the tegumentary opening being enlarged as much as appeared necessary in its withdrawal. The forefinger was now removed from the rectum, and passed into the wound, with the nail in the groove of the staff, which thus formed an accurate guide for the director, which, being made with a handle at right angles, was passed along the groove into the bladder. The assistant was now directed to pull the staff gently but firmly upwards towards the symphysis pubis, whilst I pulled the director gently downwards, and the forefinger of the left hand, being passed between these two instruments, was gently wormed between them with a twisting motion, dilating the parts as it proceeded until the neck of the bladder was reached, when both staff and director were withdrawn, and the dilatation was continued still further by rotating and moving the finger from side to side. The forceps were now introduced upon the finger, which was withdrawn as they passed into the bladder, so that to the present time no urine had escaped. The stone having been detected, the blades of the forceps were separated, when the gush of urine carried it between them, and with gentle traction it was removed. As was anticipated it proved of considerable size, measuring two inches long and one inch wide, and weighing 240 grains; it was of the triple phosphate variety. The hæmorrhage was of the most trifling description, and beyond the smarting attendant upon a wound he hardly suffered anything. There was no involuntary escape of urine after the operation, but it was passed at will, for the first week through the wound, but afterwards per urethram. Eight days from the operation he was walking about the ward, and in a fortnight was discharged cured.

The second case occurred in a spare, feeble man, aged sixtyfive, who had suffered from stone for four years prior to his admission. The urethra admitted a full-sized sound, and the prostate was perfectly healthy. The bladder was, however, considerably contracted, not holding more than four ounces of urine; and the stone, which was readily detected, was large and dense. The same proceedings were adopted as have been 234 already described; but the stone, proving even larger than was anticipated, eluded the blades of the forceps. A large pair were consequently had recourse to, and the stone removed. It was found to measure two inches and a quarter long by one inch and a half in breadth, and weighed 570 grains. It was of the oxalate of lime variety, coated with phosphates. The patient was comfortable during the evening, and passed his urine at will. He was, however, seized in the morning with a rigor, and died suddenly.

The post-mortem was made twenty-eight hours after death, and the bladder having been removed, the incision was found to be exactly in front of the prostate. The bladder was now cut into, and the mucous membrane corresponding to the neck was found to be congested and slightly torn, not, however, extending into the prostate gland, and much less than is met with in the lateral operation. The kidneys were in an advanced stage of cystic disease; the heart fatty; but the other organs were healthy.

The third case occurred in my private practice, in the person of a gentleman aged seventy-five, of spare habit, who had suf. fered from diseased prostate more or less for the last eight years, during which time he had occasional hæmorrhage, some. times slight, and sometimes sufficiently severe to call for the exhibition of gallic acid, the bleeding being at all times pro. voked by any extra walking or jolting exercise, Although there was no pain at the extremity of the penis after micturition, yet the symptoms to some extent simulated those of stone, and the bladder was from time to time carefully examined both by myself and others, without, however, detecting any foreign body. Early in 1859, while at his seat in the conntry, he was attacked with intlammation of the bladder, characterized by rigors, great frequency of micturition, spasms of a most violent character, and occasional pain at the ex. tremity of the penis, the urine depositing the usual amount of muco-purulent, tenacious deposit. Suitable remedies were had recourse to, and in the course of three months he recovered; the spasms entirely subsided, the urine regained its bealthy character, but the difficulty of expulsion had so far increased as to prevent his passing more than an ounce at a time. He was therefore directed to pass bis own catheter three or four times in the day and night, which be accomplished without either difficulty or suffering. In the winter of 1859 , being again in the country, he had another but more severe attack, which apparently arose from standing on damp ground, and it was evident, from a sudden discharge of pus and extreme tenderness of the prostate, that an abscess of that gland had formed and burst. His symptoms were now very distressing, the bladder much more irritable, and the pain at the extremity of the penis more decided; and being now unable to pass any urine naturally, he was compelled to rely entirely upon the catheter, which was passed every three hours. The bowels were daily relieved by enemata. The horizontal position was maintained, and all the known remedies had recourse to, belladonna, copaiba, and chlorodyne giving the greatest relief.

In the spring of the present year he was removed to town, the frequent and almost irresistible urgencies continuing, and the pain at the extremity of the penis being more acute. Opium, in the form of suppositories, was the only drug that now afforded the slightest relief.

On Sunday, June 15th, after violently straining at stool, the bladder became more than usually irritable; and being requested to pass his gum catheter, I immediately detected a calculus, rough, and so far as could be ascertained by such an instrument, not very large. A consultation with Mr. Arnott and Mr. Cæsar Hawkins was held; and as lithotrity offered no chances of relief, Allarton's operation was decided upon.

On June 27th he was placed under the influence of chloro. form, and the operation, as already detailed, was performed. Not the slightest difficulty was experienced in reaching the neck of the bladder, but the size of the prostate prevented the interior being explored, or the stone being felt with the finger. The forceps were consequently substituted, and being buried to a considerable depth, a stone was canght and removed, proving large, smooth, and polished. Another was sought for and removed, which bore an accurate resemblance to the first. It was, therefore, evident there must be a third, which, after slight difficulty, was also included between the blades of the forceps, but being larger than either of the former ones, it required some little patience and gentle traction to remove it. The parts, however, yielded, and the third, somewhat roughened, stone was now abstracted. The first measured $1 \frac{3}{8}$ in. by $1 \frac{1}{2}$ in.; the second, $1 \frac{3}{8}$ in. by $1 \frac{3}{4}$ in.; and the third, $1 \frac{5}{8}$ in. by $1 \frac{1}{2}$ in.; the weight of the three being 960 grains. The incision was insignificantly small; the hæmorrhage very trifling; and 
my patient being now placed in bed, shortly recovered from the effects of the chloroform, and simply complained of the slight smarting of the wound. The neck of the bladder retained its contractility, and there was not any involuntary escape. The suppository was introduced as usual; and, excepting when the urine was withdrawn, he slept tranquilly. For the first three days he progressed in the most favourable manner; the intervals were increased, the catheter being introduced every four, instead of every three, hours; the spasms were less frequent and less intense, and he was nearly relieved from the pain he had previously experienced, when, on the fourth day, he was seized with rigors, extreme and urgent pain in the region of the stomach, vomiting, and his pulse, which was exceedingly weak, rose to 130 ; skin hot; countenance anxious; and the urine presenting an appearance of bloody jelly. Opium and stimulants were administered, the bladder was injected with tepid water, and he rallied. He, however, continued exceedingly ill for three or four days, when the attack gradually subsided, the urine became more natural, but the spasms of the bladder recurred; and fearing the possibility of a calculus having descended from the kidney, he was again examined, under the influence of chloroform, without however discovering any foreign body; a roughness was detected with the gum-elastic catheter, but not with the sound, and in all probability depended upon a calcareous coating of some portion of the mucous membrane; indeed, this was subsequently ascertained to be the case, for, upon introducing a lithotrity spoon, a portion of gritty matter was removed, and eventually the corresponding mucous surface, coated with phosphates, came away in the eye of the catheter. Small particles of the same deposit have from time to time eseaped. The frequency and spasms have now entirely subsided; he is enabled to pass per urethram from two to three ounces of urine; the bladder will retain from ten to twelve ounces; the wouad has so far healed as to be hardly perceptible, and when necessary he can intro duce his own catheter. The bowels, which have hitherto required enemata of water, have acted naturally since taking the confection of seuna; and an examination per anum proves the prostate to be diminished in size. He is daily gaining flesh and strength, and when the weather will permit drives out.

The present cases have been described simply as examples to prove that large calculi and an enlarged prostate form no bar to the operation, and, as far as they go, establish the facility with which a large stone can be removed without injury to the neck of the bladder. It is true that the mortality is about the average; but as in the fatal case there was probably sufficient cause in the state of the kidneys and heart superadded to the rigor, from which persons in advanced years frequently die, I cannot consider it as in any manner militating against the operation.

The case of the boy was interesting in showing how circumstances may alter and modify symptoms generally relied upon as characteristic of stone. The pain at the extremity of the penis was the exception and not the rule, and evidentily depended upon the stone generally occupying the same position and requiring to be displaced before the sound could be fairly introduced. The diagnosis was correct in reference to its size, which it must be admitted very far exceeded the average of such cases at such an age.

In the second case, the facility with which the stone was detected, and the ringing sound, afforded sufficient evidence of its size and density to preclude any advantage from lithotrity.

The third case must be considered as the most important of the three. The size of the prostate-which did not permit the finger to reach the bladder after the necessary incisions had been made, the long duration of the disease, the inability to pass any urine without the introduction of a catheter, the irritable state of the bladder, the emaciated condition of my patient, and the presence of three such very large calculi, were sufficient to test the operation to the utmost. I may mention that this gentleman had been subject to severe bilious attacks which very much resembled the one that supervened on the fourth day, and that the issue of the case proves the symptoms to have depended upon a deranged liver.

I have described the operation as it was performed; and although the precaution of introdncing the finger between the director and the sound may rot be absolutely necessary, yet I am convinced it simplifies the operation to such a degree that no surgeon of common intelligence need fear undertaking it. The extraction of the stone requires care and gentleness. A minute lost is a minute gained, if a large calculus can be re. moved through the neck of the bladder without injury; and I feel convinced this can always be effected if the necessary care is exercised. In almost all the descriptions of the ordinary forms of operating, the direction is, to have a large external wound. Such is not necessary; and if a stone can be removed, without bruising, through a moderate wound, it is certainly better than making a large one.

From all that I have yet seen of Mr. Allarton's operation, I consider it a most valuable one: the wound is less; the hæmorrhage is less; the constitutional disturbance is less; there is no chance of infiltration of urine; and, as a matter of comfort to the patient, the ability to retain the urine is of the utmost value and importance.

Parliament-street, August, 1850.

\section{REPORT OF}

\section{TWO CASES OF CONICAL CORNEA SUC-} CESSFULLY TREATED BY OPERATION.

By GEORGE LAWSON, EsQ, F.R.C.S.,

SURGION TO THE GREAT NORTHERN HOSPITAL, AND CLINICAL ASSISTANT DO THE ROYAL LONDON OPHTHALMIO HOSPITAL

IN a paper published by Mr. Bowman in the "Ophthalmic Hospital Reports" for Oct., 1859, he describes a mode of treatment he had been induced to pursue in cases of conical cornca. It consisted in altering the shape of the pupil, by converting the natural circular aperture which is placed immediately behind the apex of the cone of the cornea into a slit, which may be made either vertical or horizontal as the surgeon may desire. The operation is performed by drawing the iris with a Tyrrell's hook through a small incision made at the extreme margin of the cornea by a broad needle, and then fixing it there by $\mathrm{Mr}$. Critchett's method of tying it with a piece of very fine thread. If a vertical pupil is desired, a portion of the iris is first drawn directly downwards, and there fastened, and at the expiration of eight or ten days, or when the eye has become perfectly quiet, a similar proceeding is adopted in the upward direction, and a slit-like pupil results. It becomes, as he there suggested, a matter of experience to determine what alteration in the shape of the pupil is most condusive to improve vision in this class of cases.

As few patients suffering from conical cornea have yet been snbmitted to this plan of treatment, a record of those who have been operated on, with the result which has accrued from the operation, becomes not only interesting, but extremely useful in deciding what amount of good we may hope to derive from surgical interference.

The two following eases I operated on, one in December and the other in January last; and as eight months have now expired, I may justly speak of the benetit which each has derived as permanent. First, it will be observed in reading the cases that in each the conicity has been much diminished-the apex of the cone has become rounded off into the general eurvature of the cornea, and the central opacity is scarcely visible.

It is very probable that this arrest of the increasing conieity of the cornea is dependent upon an alteration of the direction of the pressure within the globe, which is greatest in the normal condition of the eye in the antero-posterior diameter, in - a line drawn from behind and passing forwards through the centre of the pupil to the cornea,-to that point, in fact, which forms the apex of the cone of the cornea in eyes which are affected with this disease. Mr. Halke has demonstrated by microscnpical examination that this peculiar condition of cornea is dependent on disease localized in the central portion, and which, yielding to the pressure from within, bulges, and becomes extremely attenuated. If, therefore, by any means, we can alter the direction of this pressure so as to cause it to bear on a healthy portion of the cornea, we certainly place the eye in a more favourable condition; and it appears to me that the slit-like pupil, particularly if made a little to the inner or nasal side, not only allows a more healthy portion of the cornea to receive the pressure from within, but, from its increased size, distributes it over a larger surface, and thus deprives it of a portion of its force.

The next question is concerning the improvement of sight to be gained. In each of the two cases which I am about to quote, distant vision was manifestly improved. In the first case near vision also was benefited, but in the second case the improve. ment for near objects was not so great as that for distant ones. The improvement of vision, I believe, depends on the rays of 